\title{
Effect of the consumption of tomato paste on plasma prostate-specific antigen levels in patients with benign prostate hyperplasia
}

M.S. Edinger ${ }^{1}$ and W.J. Koff ${ }^{1,2}$

\section{Correspondence \\ M.S. Edinger \\ Rua Demétrio Ribeiro, 244/603 \\ 90010-312 Porto Alegre, RS \\ Brasil \\ E-mail: magdaed@terra.com.br \\ Presented at the XXX Brazilian Meeting of Urology, Brasília, DF, Brazil, October 22-27, 2005 , XXVIII Meeting on Nutrition, Porto Alegre, RS, Brazil, August 11-12, 2005 and XXV Scientific Week of HCPA, Porto Alegre, RS, Brazil, September 12-16, 2005.}

Research supported by FIPE/HCPA, CAPES, and Oderich S/A.

Received September 23, 2005 Accepted May 18, 2006

\author{
1Programa de Pós-Graduação em Medicina: Ciências Médicas, \\ Faculdade de Medicina, Universidade Federal do Rio Grande do Sul, \\ Porto Alegre, RS, Brasil \\ ${ }^{2}$ Departamento de Urologia, Hospital de Clínicas de Porto Alegre, \\ Porto Alegre, RS, Brasil
}

\begin{abstract}
The consumption of tomatoes and tomato products has been associated with a reduced risk of prostate cancer. We observed a decrease of $10.77 \%$ in prostate-specific antigen (PSA) levels in patients with benign prostate hyperplasia who were submitted to daily ingestion of tomato paste. This was an experimental rather than a controlled study with a sample of 43 men ranging in age from 45 to 75 years, all with histological diagnoses of benign prostate hyperplasia and plasma PSA levels of 4-10 ng/mL. All patients received $50 \mathrm{~g}$ of tomato paste once a day for 10 consecutive weeks and PSA levels were analyzed before, during and after the consumption of tomato paste. ANOVA for repeated measures was used to compare PSA levels before, during and after the consumption of tomato paste. The mean \pm SD PSA level was $6.51 \pm 1.48 \mathrm{ng} / \mathrm{mL}$ at baseline and $5.81 \pm 1.58 \mathrm{ng} / \mathrm{mL}(\mathrm{P}=0.005)$ after 10 weeks. Acceptance was good in 88.3, regular in 9.3, and poor in $2.3 \%$ of the patients. Dietary ingestion of $50 \mathrm{~g}$ of tomato paste per day for 10 weeks significantly reduced mean plasma PSA levels in patients with benign prostate hyperplasia, probably as a result of the high amount of lycopene in tomato paste. This was not a prostate cancer prevention study, but showed some action of tomato paste in prostate biology. The development of prostate cancer is typically accompanied by an increase in plasma PSA levels, thus any intervention that affects plasma PSA levels can suggest an impact in the progression of disease.
\end{abstract}

Key words

- Prostate cancer

- Prostate-specific antigen

- Tomatoes

- Tomato paste

- Lycopene
The concentration of prostate-specific antigen (PSA) has been used as a tumor marker in the progression of prostate cancer, with high values possibly suggesting the onset of the disease (1). PSA is not really a pure marker for prostate cancer since it is already produced by normal prostatic cells.
However, it has been successfully used as a parameter for prostate biopsy when present at levels higher than $4 \mathrm{ng} / \mathrm{mL}$. More recently, even lower values have been suggested to indicate the possibility of the disease. The low specificity of this test has challenged urologists to search for other more specific 
markers of prostate cancer or PSA fractions and other parameters such as density, speed of PSA increase and free PSA as a means of improving the performance of this worldwidely used test (2). We also know that benign prostate hyperplasia (BPH) is followed by an increase in plasma PSA levels that may be related to $\mathrm{BPH}$ volume (3).

Many studies have associated consumption of tomatoes and tomato products with a reduced risk of prostate cancer (4). The hypothesis is that lycopene, the main carotenoid in tomatoes, has a direct effect on the prostate $(5,6)$. There is also evidence that tomatoes may contain other compounds in addition to lycopene that may influence prostate carcinogenesis (7).

The amount of lycopene in fresh tomatoes depends on their variety, ripeness levels and environmental conditions under which the fruit was grown (8). Nonetheless, industrialized tomato products or cooked tomatoes have been shown to contain the largest amount of bioavailable lycopene (9). The thermal process breaks down cell walls and permits the extraction of lycopene from the chloroplasts (10).

Many mechanisms proposed for lycopene play a role in the prevention of prostate cancer: antioxidant function (it is the carotenoid with the best ability to quench singlet oxygen), inhibition of cell cycle progression, increased apoptotic index, increased gap-junctional communication, inhibition of

Table 1. Nutritional information for $50 \mathrm{~g}$ of tomato paste.

\begin{tabular}{lr} 
Calories & $18 \mathrm{kcal}$ \\
Carbohydrates & $2.8 \mathrm{~g}$ \\
Proteins & $1.3 \mathrm{~g}$ \\
Total fat & $0.2 \mathrm{~g}$ \\
Saturated fats & $0.1 \mathrm{~g}$ \\
Sodium & $180 \mathrm{mg}$ \\
Lycopene & $13 \mathrm{mg}$ \\
\hline
\end{tabular}

Data are reported as mean values for 5 cans containing $350 \mathrm{~g}$ each. The lot came from the same tomato farm. insulin-like growth factor-1 signal transduction, inhibition of interleukin-6 expression, induction of phase II enzymes, and inhibition of androgen activation and signaling (5). Perhaps the latter is of the greatest importance considering the fact that male hormones have a significant influence on the development of prostate cancer (11).

The objective of the present study was to measure PSA levels in patients with a histological diagnosis of BPH who were submitted to a daily diet containing lycopene-rich tomato paste.

In this non-controlled study, 43 men ranging in age from 45 to 75 years diagnosed with BPH (histological criterion by prostate biopsy done at most one year before) and plasma PSA levels between 4 and $10 \mathrm{ng} / \mathrm{mL}$ were monitored. None of the patients took hormones, finasteride or lycopene supplements.

All patients were instructed to consume $50 \mathrm{~g}$ of tomato paste (3 soup spoons) once a day for 10 consecutive weeks. The paste could be mixed with warm or cold food, but not boiled. It could also be taken as tomato juice (blending tomato paste with a glass of water), or even pure according to patient preference. The distribution of this daily quantity was also optional; the patient was permitted to choose the amount of tomato paste to eat at any time - either once, twice or three times a day. No diet orientation was given; all patients could keep their normal diets and simply add tomato paste to it.

The tomato paste brand used was Oderich S/A (São Sebastião do Caí, RS, Brazil). This product is a result of the concentration of tomato pulp taken from ripe and safe fruit obtained by an appropriate technological process with $1-3 \%$ sodium chlorite added to it. The result is a soft red mass with a characteristic tomato taste and smell.

The tomato paste lot used in this study provided a dose of lycopene of approximately $13 \mathrm{mg}$ per day. The quantity of lycopene was calculated by a methodology de- 
scribed by Fish et al. (12). In addition to calculating the amount of lycopene, the nutritional value of $50 \mathrm{~g}$ tomato paste was also analyzed, as described in Table 1.

The PSA exams were carried out 30 days before the beginning of consumption and after 4 and 10 weeks of consumption. All exams were performed with the Elecsys ${ }^{\circledR}$ total PSA immunoassay from Roche ${ }^{\circledR}$ (Roche Diagnostics GmbH, D-68298 Mannheim, Germany) and the Elecsys ${ }^{\circledR} 2010$ analyzer. The samples were analyzed from April 2003 to May 2004. Intra-assay reproducibility was determined with Elecsys ${ }^{\circledR}$ reagents by Roche $^{\circledR}$ in which a $2.9 \%$ variation coefficient was obtained for a mean of PSA values from 4.76 to $17.2 \mathrm{ng} / \mathrm{mL}$. Inter-assay variation was determined by the Laboratory of Hospital de Clínicas de Porto Alegre (Porto Alegre, RS, Brazil) obtaining a mean coefficient variation of $5.74 \%$.

Age is reported as mean $\pm \mathrm{SD}$ and age range, acceptance variables (good, regular, or bad) and consumption modes (pure, mixing with foods or mixed) are reported as simple absolute frequency and percentages.

Data were analyzed statistically by ANOVA for repeated measures to compare the plasma PSA levels before, during and after the consumption of tomato paste, with the level of significance set at $\mathrm{P}<0.05$. ANOVA with a level of significance of 0.05 was used to compare the consumption mode and the plasma PSA levels. PSA values are reported as means, medians and SD.

Average age was 63.7 years and age range was predominantly 60-70 years (19 patients or $44.2 \%$ ).

When asked about the acceptance of the product at the end of the study, $38(88.3 \%)$ patients considered it good, $4(9.3 \%)$ considered it regular and only 1 (2.3\%) considered it poor.

Regarding consumption modes, 25 (58.1\%) patients consumed tomato paste with other foods, $13(30.2 \%)$ consumed it pure or with water and $5(11.6 \%)$ consumed it both ways (mixed mode). Consuming tomato paste with water to make a juice to drink during a meal was considered to be consumption mixed with food. Consumption was only considered to be pure when the product was consumed independently of any other food.

The tomato paste that was mixed with other foods reduced the levels of PSA in relation to the other modes of consumption, although the difference was not significant $(\mathrm{P}=0.148)$, possibly because of the small sample. This probable reduction may occur because of the better absorption of lycopene when it is consumed together with oils (13).

In this sample, mean plasma PSA levels were reduced from $6.51 \pm 1.48$ to $5.81 \pm 1.58$ $\mathrm{ng} / \mathrm{mL}(\mathrm{P}=0.005)$, with a power of $87.11 \%$. Basal plasma PSA levels did not differ significantly $(\mathrm{P}=0.876)$ from PSA levels determined after the 4 th week, but differed significantly from the 4 th to the 10 th week $(\mathrm{P}=$ 0.002). The total results of the test and PSA values are presented in Table 2.

Some minor adverse effects were noted, namely skin itching $(4.6 \%)$, heartburn $(7 \%)$ and flatulence $(2.3 \%)$.

No experimental study was found in the scientific literature on lycopene or tomatoes and tomato products consumed by men with a histological diagnosis of BPH. Therefore, all human studies discussed in the present study concern patients with prostate cancer.

A study observed 32 men with prostate cancer who also received $30 \mathrm{mg}$ of lycopene

Table 2. Prostate-specific antigen (PSA) values of the study subjects before, during, and after the consumption of tomato paste.

\begin{tabular}{lccc}
\hline Variables & $\begin{array}{c}\text { Basal PSA } \\
(\mathrm{ng} / \mathrm{mL})\end{array}$ & $\begin{array}{c}\text { PSA 4th week } \\
(\mathrm{ng} / \mathrm{mL})\end{array}$ & $\begin{array}{c}\text { PSA 10th week } \\
(\mathrm{ng} / \mathrm{mL})\end{array}$ \\
\hline Mean $\pm \mathrm{SD}$ & $6.51 \pm 1.48$ & $6.47 \pm 2.06$ & $5.81 \pm 1.58^{*}$ \\
$95 \% \mathrm{Cl}$ & $6.05-6.97$ & $5.83-7.10$ & $5.32-6.30$ \\
Median & 6.52 & 6.09 & 6.21 \\
Minimum value & 4.21 & 1.63 & 1.40 \\
Maximum value & 10 & 11.76 & 8.79
\end{tabular}

*The PSA value for 10 weeks was significantly lower than basal and 4 week values ( $P$ $<0.005$ ), which were not different from each other (ANOVA). 
through tomato paste added to different preparations for 3 weeks before prostatectomy. The concentrations of lycopene increased in the plasma and prostate (1.97 and 2.92 times, respectively; $\mathrm{P}<0.001)$, and PSA levels decreased to $17.5 \%(\mathrm{P}<0.002)$ (6). Our study showed a decrease in PSA levels to $10.77 \%$, although the study subjects did not have a diagnosis of prostate cancer.

An experimental study with mice published in 2003 offers some interesting data on a diet based on tomatoes and lycopene supplement. The mice were fed three types of diet regimens: diet restriction, lycopene supplement and tomato powder. It was observed that the diet containing tomato powder but not a lycopene supplement inhibited prostate cancer, suggesting that tomatoes contain substances, in addition to lycopene, that may modulate prostate carcinogenesis (14).

Tomato paste was chosen for the present study for the following reasons: a) the use of one food, considering that the absorption of primary food is more effective than food supplements (15); b) tomato paste is rich in lycopene $(9,16)$, and c) possibly, tomatoes have other properties besides lycopene that can affect blood PSA levels $(7,14)$.

The development of prostate cancer is typically accompanied by an increase in plasma PSA levels (17). Perhaps it would be reasonable to assume that some intervention that affects plasma PSA levels can have an impact on the natural history of this disease (18). The gene encoding PSA is one of the well-known androgen target genes (19). Thus, the decrease in serum PSA level may mean an anti-androgen effect of lycopene in the human prostate with the potential to prevent prostate cancer (5).

In order to obtain strong evidence that tomato paste decreases the levels of PSA in plasma, thus being able to prevent prostate cancer, it would be ideal to carry out a major clinical, randomized, multicentric, doubleblind trial for several years. But the difficulty in achieving this is obvious: it is difficult to double-blind the consumption of tomato paste. One way of doing this would be to carry out a study using capsules containing tomato components such as selenium and vitamin E, as in the SELECT study (20).

\section{Acknowledgments}

We thank Mr. Claudio Oderich from Conservas Oderich S.A., São Sebastião do Caí, RS, Brazil, and Professor Adriano Brandelli, Instituto de Ciências e Tecnologia de Alimentos, Universidade Federal do Rio Grande do Sul, Porto Alegre, RS, Brazil.

\section{References}

1. Balk SP, Ko YJ, Bubley GJ. Biology of prostate-specific antigen. $J$ Clin Oncol 2003; 21: 383-391.

2. Thompson I, Leach RJ, Pollock BH, Naylor SL. Prostate cancer and prostate-specific antigen: the more we know, the less we understand. J Natl Cancer Inst 2003; 95: 1027-1028.

3. Stamey TA, Caldwell M, McNeal JE, Nolley R, Hemenez M, Downs $J$. The prostate specific antigen era in the United States is over for prostate cancer: what happened in the last 20 years? J Urol 2004; 172: $1297-1301$.

4. Etminan M, Takkouche B, Caamano-Isorna F. The role of tomato products and lycopene in the prevention of prostate cancer: a metaanalysis of observational studies. Cancer Epidemiol Biomarkers Prev 2004; 13: 340-345.
5. Wertz K, Siler U, Goralczyk R. Lycopene: modes of action to promote prostate health. Arch Biochem Biophys 2004; 430: 127-134.

6. Bowen P, Chen L, Stacewicz-Sapuntzakis M, Duncan C, Sharifi R, Ghosh L, et al. Tomato sauce supplementation and prostate cancer: lycopene accumulation and modulation of biomarkers of carcinogenesis. Exp Biol Med 2002; 227: 886-893.

7. Campbell JK, Canene-Adams K, Lindshield BL, Boileau TW, Clinton SK, Erdman JW Jr. Tomato phytochemicals and prostate cancer risk. J Nutr 2004; 134: 3486S-3492S.

8. Hart DJ, Scott KJ. Development and evaluation of HPLC method for the analysis of carotenoid in foods, and the measurement of carotenoid content of vegetables and fruits commonly consumed in the UK. Food Chem 1995; 54: 101-111. 
9. Gartner C, Stahl W, Sies H. Lycopene is more bioavailable from tomato paste than from fresh tomatoes. Am J Clin Nutr 1997; 66: 116-122.

10. Gann PH, Ma J, Giovannucci E, Willett W, Sacks FM, Hennekens $\mathrm{CH}$, et al. Lower prostate cancer risk in men with elevated plasma lycopene levels: results of a prospective analysis. Cancer Res 1999; 59: 1225-1230.

11. Brawley OW. Hormonal prevention of prostate cancer. Urol Oncol 2003; 21: 67-72.

12. Fish W, Pearkins-Veazie P, Collins J. A quantitative assay for lycopene that utilizes reduced volumes of organic solvents. J Food Compost Anal 2002; 15: 309-317.

13. Stahl W, Sies H. Uptake of lycopene and its geometrical isomers is greater from heat-processed than from unprocessed tomato juice in humans. J Nutr 1992; 122: 2161-2166.

14. Boileau TW, Liao Z, Kim S, Lemeshow S, Erdman JW Jr, Clinton SK. Prostate carcinogenesis in N-methyl-N-nitrosourea (NMU)-testosterone-treated rats fed tomato powder, lycopene, or energy-restricted diets. J Natl Cancer Inst 2003; 95: 1578-1586.

15. Block G, Sinha R, Gridley G. Collection of dietary-supplement data and implications for analysis. Am J Clin Nutr 1994; 59: 232S-239S.

16. Shi J, Le MM. Lycopene in tomatoes: chemical and physical properties affected by food processing. Crit Rev Food Sci Nutr 2000; 40: 1 42.

17. Catalona WJ, Partin AW, Slawin KM, Brawer MK, Flanigan RC, Patel A, et al. Use of the percentage of free prostate-specific antigen to enhance differentiation of prostate cancer from benign prostatic disease: a prospective multicenter clinical trial. JAMA 1998; 279: 1542-1547.

18. Shike M, Latkany L, Riedel E, Fleisher M, Schatzkin A, Lanza E, et al. Lack of effect of a low-fat, high-fruit, -vegetable, and -fiber diet on serum prostate-specific antigen of men without prostate cancer: results from a randomized trial. J Clin Oncol 2002; 20: 3592-3598.

19. Siler U, Barella L, Spitzer V, Schnorr J, Lein M, Goralczyk R, et al. Lycopene and vitamin $E$ interfere with autocrine/paracrine loops in the Dunning prostate cancer model. FASEB J 2004; 18: 1019-1021.

20. Klein EA, Thompson IM, Lippman SM, Goodman PJ, Albanes D, Taylor PR, et al. SELECT: the next prostate cancer prevention trial. Selenum and Vitamin E Cancer Prevention Trial. J Urol 2001; 166 : 1311-1315. 